\title{
BEST STRATEGY FOR THE DEVELOPMENT OF A SEISMIC PREVENTION PLAN
}

\section{Enzo Mantovani, ${ }^{1}$ Marcello Viti, ${ }^{1}$ Daniele Babbucci, ${ }^{1}$ Caterina Tamburelli, ${ }^{1}$ Nicola Cenni ${ }^{2}$}

\author{
${ }^{1}$ Dipartimento di Scienze Fisiche, della Terra e dell'Ambiente, Università di Siena; \\ ${ }^{2}$ Dipartimento di Fisica e Astronomia, Università di Bologna, Italy
}

\begin{abstract}
An effective mitigation of seismic risk in Italy can hardly be obtained without a tentative recognition of few priority zones, where the limited resources available in the short term can be concentrated. A reliable recognition of the zones where the probability of major earthquakes is highest must be carried out by a deterministic approach, exploiting the profound knowledge acquired about the present seismotectonic context in the zones involved. Some years ago, this kind of procedure led us to identify the central-northern Apennines (i.e. the zone hit by the recent major earthquakes, 2016 and 2017) as the Italian area most prone to next strong shocks. The reliability of the methodology here proposed is also supported by the fact that the implications of the adopted tectonic setting can provide plausible and coherent explanations for the spatio-temporal distribution of major earthquakes in the central Mediterranean area in the last six centuries.
\end{abstract}

Key words: Seismic Hazard, Prevention, Seismotectonics.

The economic resources that would be necessary to obtain a significant reduction of the seismic risk in the whole Italian country are considerably greater than the ones that can be made available in the short term. Thus, a satisfactory prevention plan can only be developed in a very long time (at least several decades). However, one must be aware that the effectiveness of such operation will strongly depend on how the resources are gradually distributed in space and time over the Italian territory. If, for instance, each annual contribution were homogeneously distributed all over the Italian seismic zones, the reduction of seismic risk achieved in each single zone would be very poor for a long period. Alternatively, one could initially concentrate the available resources in limited zones where the interventions may be considered more urgent. For instance, this kind of choice has been adopted for distributing some funds in the aftermath of the 2009, L'Aquila earthquake (Legge 24 Giugno 2009, n. 77). In that case, it was decided to privileging the zones where the seismic hazard provided by the current probabilistic maps $[1,2]$ is highest. The result of such choice is reported in Table 1, where it is possible to see that some regions (the ones hit by the strongest historical earthquakes: Calabria, Campania, and Sicilia) have been assigned much more (up to about 20 times) funds with respect to the other regions.

However, in our opinion, the above criterion is questionable, since the fact that a given zone experienced major historical shocks does not imply that prevention in such zone is more urgent than in other zones. For instance, one could note that the most financed regions (Calabria, Campania and Sicilia) have not been interested by recent strong shocks, whereas the regions that hosted the last 9 strong shocks (Abruzzo 2009, EmiliaRomagna 2012 and central Italy 2016-17) have only obtained a medium size financial support.

Thus, we argue that a much more efficient prevention plan could be organized if reliable information would be available about where the next strong shocks in Italy may most probably occur. Many attempts at obtaining such information have been made in the past [3-5] but the scarce correspondence that has so far occurred between the proposed predictions and the real distribution of seismicity has considerably discouraged such kind of investigations. However, one must consider that those disappointing results can be imputed to the fact that the methodology so far adopted is based on statistical analyses, i.e. an approach which is based on assumptions in clear contrast with the real nature of earthquakes [6]. Since it is well known that earthquakes are deterministic phenomena, closely connected with the progressive development of crustal deformations, any attempt at recognizing the future paths of seismicity in the study area can provide reliable results only if it is carried out by an adequate deterministic approach, based on a profound knowledge of the ongoing tectonic context. This kind of approach has been described in some publications [7-9].

\section{Correspondence to:}

Enzo Mantovani

Dipartimento di Scienze Fisiche della Terra e dell'Ambiente, Università degli Studi di Siena

Via Laterina 8, 53100 Siena, Italy

Tel- Fax: +39.0577.233826

E-mail: enzo.mantovani@unisi.it 
In this note, we report a synthesis of the proposed procedure, in particular we describe the mechanism that it is supposed to control the spatio-temporal distribution of seismicity in the central Mediterranean region and the way by which such knowledge can allow the recognition of the Italian zones most prone to the next strong earthquakes in Italy.

The ongoing tectonic context in the central Mediterranean area is sketched in Figure 1[10]. As argued in several papers [10-12], tectonic activity in the study area is mainly driven by the convergence of the confining plates, in particular by the motions of Africa and the AnatolianAegean-Balkan system with respect to Eurasia.

Such boundary conditions are mainly accommodated by the motion of the Adriatic plate (Adria), which is allowed by the decoupling earthquakes that occur along the orogenic zones which surround that plate (Figure 2) $[8,9]$. The motion of Adria is supposed to be very slow during quiescent periods, whereas it locally accelerates during co-seismic and post-seismic phases, in response to major decoupling earthquakes along the plate boundaries.

Taking into account the above tectonic context and the fact that the seismic activation of a periAdriatic sector may influence the tectonic load and thus the probability of strong shocks in the other boundary zones, one could expect to observe regularities in the spatiotemporal distribution of seismicity along the periAdriatic zones. To check the reliability of this hypothesis, we have analysed the time patterns of seismic activity in the main periAdriatic zones since 1400 A.D. (Figure $3)$. These patterns point out that in the zones considered seismicity is mostly discontinuous over time, with periods of high activity separated by almost quiescent phases.

Furthermore, one could tentatively recognize a progressive northward migration of seismic crises, along the eastern (Northern Hellenides and Dinarides) and western (Apennines and Calabria) boundaries of Adria, up to reach the northernmost boundary of Adria (Eastern Southern Alps and Northernmost Dinarides), as tentatively evidenced by the coloured strips. The features of the proposed seismic sequences suggest that each northward step of Adria (roughly 1-2 metres) takes about two centuries to achieve a full development.

The first two possible seismic sequences are identi-

Table 1. Funds assigned to the Italian regions for restoration of buldings (Legge 24 Giugno 2009, n. 77), in the period 2010- 2015.

\begin{tabular}{lcccccccc}
\hline Region & Involved & \multicolumn{3}{c}{ Average funding per municipality (Euros) } & \multicolumn{2}{c}{ Total funding } \\
& municipalities & $\mathbf{2 0 1 0}$ & $\mathbf{2 0 1 1}$ & $\mathbf{2 0 1 2}$ & $\mathbf{2 0 1 3}$ & $\mathbf{2 0 1 4}$ & $\mathbf{2 0 1 5}$ & (million euros) \\
\hline Abruzzo & 276 & 9904 & 33,949 & 44,395 & 44,395 & 44,395 & 32,382 & 57.8 \\
\hline Basilicata & 117 & 20,400 & 49,352 & 64,538 & 64,538 & 64,538 & 47,075 & 36.3 \\
\hline Calabria & 402 & 12,748 & 45,976 & 60,123 & 60,123 & 60,123 & 43,851 & 113.7 \\
\hline Campania & 426 & 7703 & 42,111 & 55,068 & 55,068 & 55,068 & 40,167 & 108.7 \\
\hline Emilia-Romagna & 283 & 6607 & 28,287 & 36,992 & 36,991 & 36,991 & 26,982 & 48.9 \\
\hline Friuli Venezia-Giulia & 202 & 7173 & 22,634 & 29,599 & 29,599 & 29,599 & 21,589 & 28.3. \\
\hline Lazio & 299 & 3829 & 26,644 & 34,973 & 34,973 & 34,973 & 25,510 & 48.1 \\
\hline Liguria & 111 & 4722 & 12,464 & 16,299 & 16,299 & 16,299 & 11,889 & 8.6 \\
\hline Lombardia & 202 & 2093 & 7374 & 9643 & 9642 & 9642 & 7033 & 9.2 \\
\hline Marche & 239 & 5762 & 25,125 & 32,856 & 32,856 & 32,856 & 23,965 & 36.7 \\
\hline Molise & 134 & 22,352 & 49,385 & 64,581 & 64,581 & 64,581 & 47,106 & 41.9 \\
\hline Piemonte & 141 & 2167 & 7356 & 9620 & 9620 & 9620 & 7017 & 6.4 \\
\hline Puglia & 84 & 18,251 & 68,620 & 89,735 & 89,735 & 89,735 & 65,453 & 35.4 \\
\hline Sicilia & 282 & 17,270 & 64,343 & 84,141 & 84,141 & 84,141 & 61,373 & 111.5 \\
\hline Toscana & 247 & 4744 & 21,662 & 28,327 & 28,327 & 28,327 & 20,662 & 32.6 \\
\hline Umbria & 92 & 14,088 & 66,899 & 87,483 & 87,483 & 87,483 & 63,811 & 37.4 \\
\hline Veneto & 335 & 3911 & 15,713 & 20,547 & 20,547 & 20,547 & 14,987 & 32.2 \\
\hline Total funding (milion euros & & 33.8 & 129.3 & 169.2 & 169.2 & 169.2 & 123.4 & 794.0 \\
\hline
\end{tabular}


fied by the grey and orange strips, even though their starting phases in the southernmost periAdriatic sectors are not very clear.

The first presumably complete sequence (green in Figure 3) may have been triggered by a considerable increase of seismic activity in the Northern Hellenides sector during the first decades of the XVII century. This triggering crisis was followed by a significant increase of seismic activity in almost all other periAdriatic zones, up to reach the northern front of Adria in the second half of the XVIII century (Figure 3 ). In this last zone, major seismic activity lasted up to about the end of the XVIII century and then underwent a drastic reduction for a relatively long period, until 1870 .

A drastic increase of seismic activity in the Northern Hellenides in the last decades of the XVIII century may have determined the beginning of a new seismic sequence (yellow in Figure 3). Other seismic periods occurred in the same zone up to the middle of the XIX century. This sequence continued to develop with several major events in the Albania, Southern Dinarides and Southern Apennines. In the Central Apennines, a relatively long period of moderate seismic activity was interrupted by a very strong shock in the

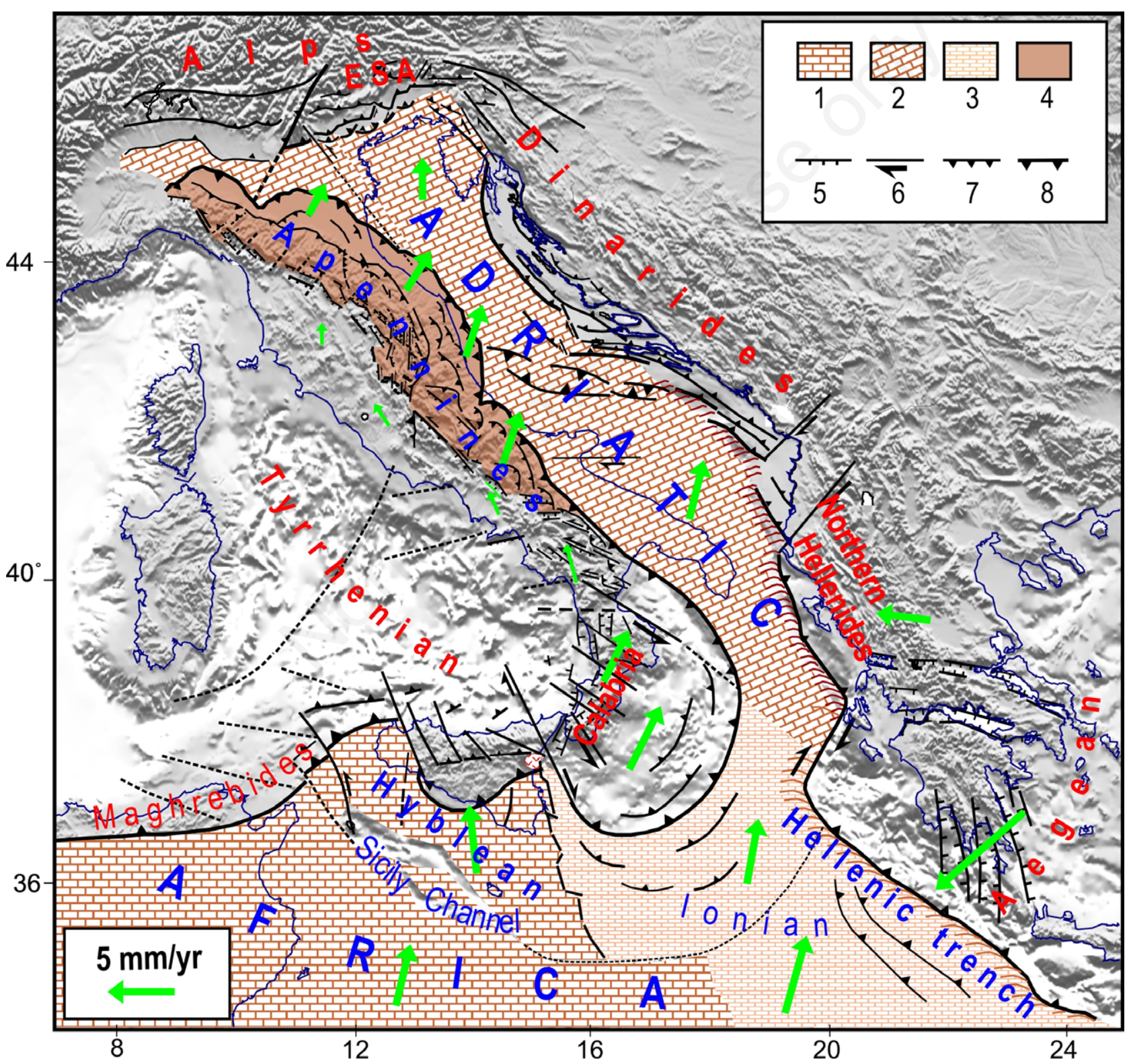

Figure 1. Sketch of the tectonic/kinematic setting in the central Mediterranean region. 1,2) African and Adriatic continental domains; 3) Ionian oceanic domain; 4) outer sector of the Apennine belt dragged and stressed by the Adriatic plate; 5-7) major extensional, transcurrent and compressional tectonic features; 8) outer front of Neogenic belts. Green arrows indicate the proposed kinematic pattern with respect to Eurasia [12,15]. ESA, Eastern Southern Alps. 
1915 (Fucino, $M=7.0$ ), which was followed by several strong earthquakes in the Northern Apennines in the period 1916-1930.

The last presumed seismic sequence (blue in Figure 3) was triggered by a phase of very high seismic activity in the Northern Hellenides around the end of the XIX century. As in previous cases the above crisis was accompanied by strong earthquakes in Calabria (1905 $\mathrm{M}=6.9$, $1908 \mathrm{M}=7.2$ ).

Then, in the first 8 decades of 1900, significant seismic activity occurred in the southern sectors of the Dinarides and Apennines, while very scarce seismic activity affected the northern periAdriatic regions, with one major seismic crisis in the Eastern Alps (1976, $M=6.5,6.0)$ and a shock (1971, $M=5.7)$ in the northernmost Apennines. This major difference between the ongoing seismic sequence (blue in Figure 3 ) and the preceding sequences (green and yellow in Figure 3 ) is better evidenced by the spatial distribution of major earthquakes (Figure 4).

The seismicity patterns shown in Figures 3 and 4 may suggest that after the 1980 the probability of major earthquakes in the central and northern Apennines was higher than in other Italian seismic zones. This prediction is based on the assumption that the tendency of seismic activity to migrate northward along in the periAdriatiac zones is systematic. Unfortunately, the limited length of the known seismic history that can be tentatively taken as reliable and complete (since 1400 A.D.) only allows the recognition of few migrating periAdriatic seismic sequences. However, it must be considered that the reliability of our assumption is also supported by the fact that the observed behaviour of seismicity is based on a physically plausible tectonic interpretation, supported by a huge amount of evidence from all branches of Earth Sciences [7,10-17].

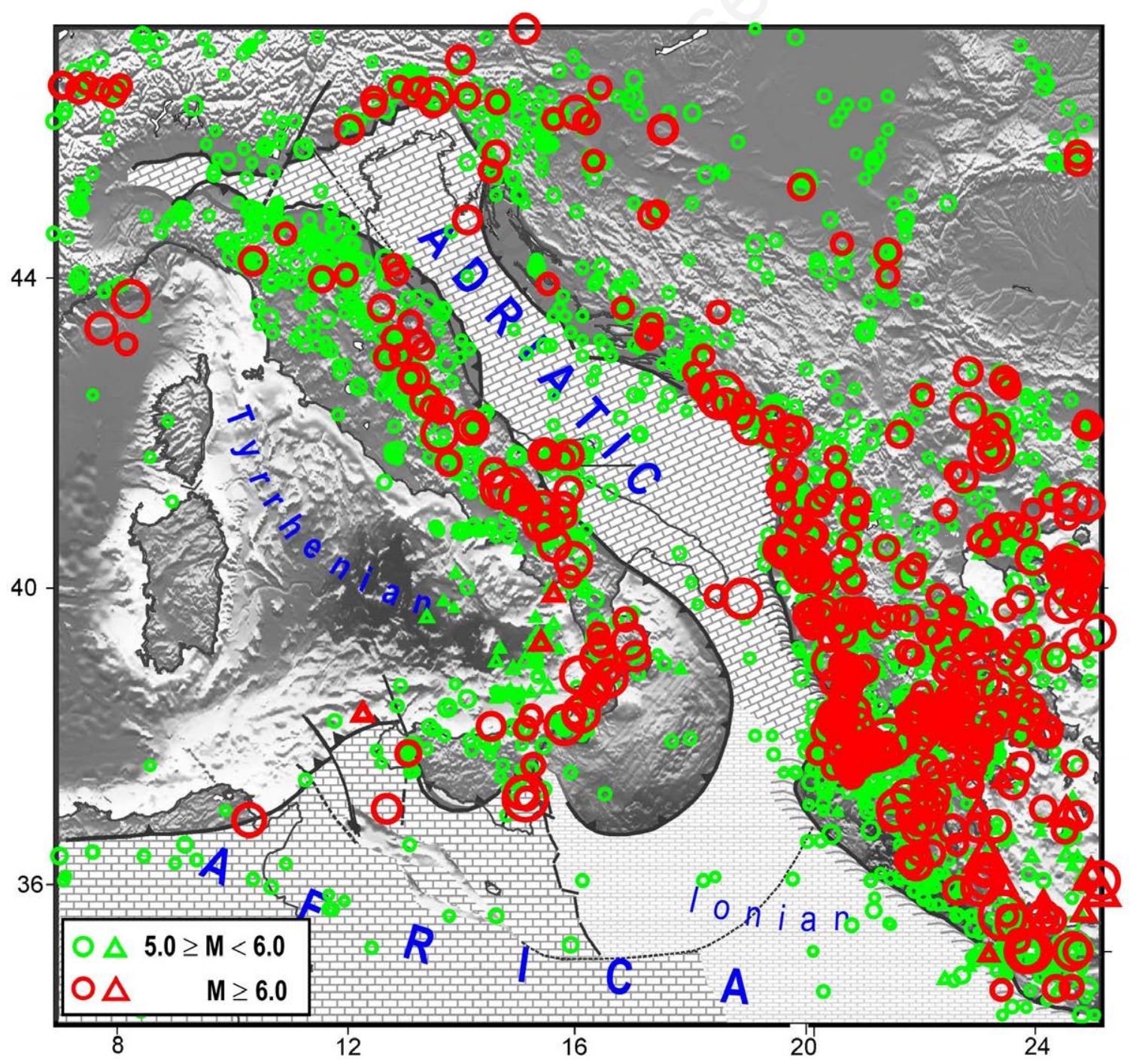

Figure 2. Distribution of major seismicity in the central Mediterranean area. Circles and triangles respectively indicate the shallow and deep $(\mathrm{h}>60 \mathrm{~km})$ earthquakes that have occurred between 1400 and 2009. Seismicity data from [8,9]. 

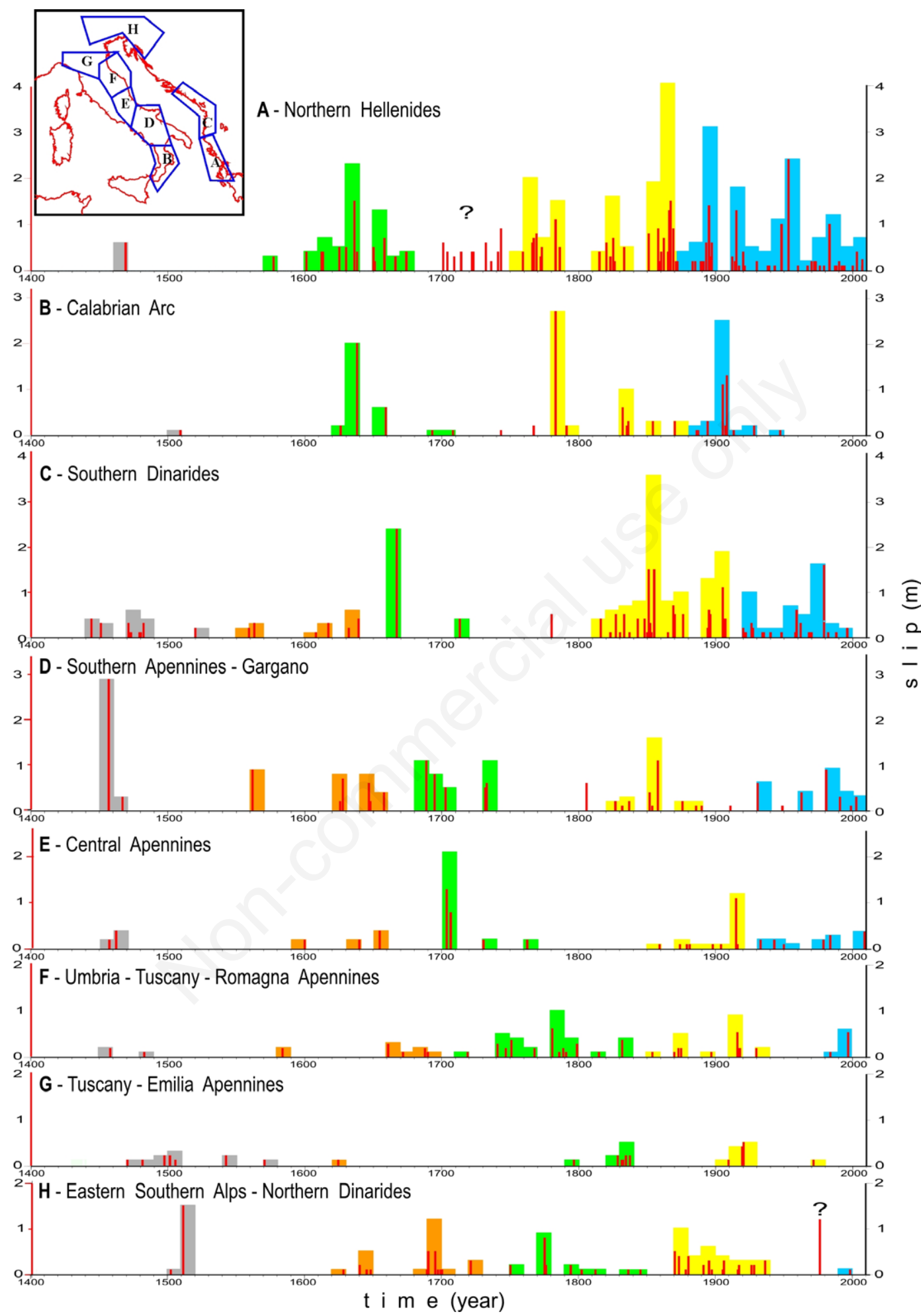

Figure 3. Time patterns of seismic slip associated with major shallow seismicity $(\mathrm{h} \leq 30 \mathrm{~km}$ and $\mathrm{M} \geq 5.5)$ that has occurred in the main periAdriatic seismic zones between 1400 and 2009. The geometries of the zones considered are shown in the inset. Red bars in the diagrams indicate the total seismic slip (metres) occurred during the related year, computed by the relation $\log _{10} u=-4.8+0.69 M$, where $\mathrm{u}$ is the average seismic slip on the fault (in metres) and $\mathrm{M}$ is the earthquake magnitude [13]. Vertical coloured bands indicate the sum of seismic slips over decades. Colours tentatively evidence the seismic sequences during which major decoupling earthquakes have undergone a progressive migration from the southern to the northern periAdriatic zones (see text for comments). Seismicity data from $[8,9]$. 
Furthermore, one should consider that notwithstanding possible ambiguities in the identification of the priority seismic zones, the strategy of privileging seismic risk reduction in few priority zones would anyway be convenient. In case the next shock does not occur in one of the zones identified (eventuality that cannot be excluded, given the complexity of the problem involved) the negative consequences of such failure would be not very important for the epicentral zone, where an almost negligible improvement of safety would have been allowed by an homogeneous distribution of resources. Instead, in case the next earthquake occurs in one of the proposed priority zones, the practical advantages would be remarkable, since the significant improvement of safety obtained for such zone could allow an appreciable reduction of casualties and damages.

Anyway, an important support to the reliability of the approach here proposed is given by the fact that the last 9 strong $(M \geq 5.5)$ shocks in Italy (Figure 5) have occurred in the central and northern Apennines, i.e. the zone recognized as most dangerous.
A detailed description of the evidence and arguments that led us to advance the above prediction is reported in some recent publications [7-9].

It is opportune to point out that no information can actually be provided about when the priority zones here recognized may be hit by major earthquakes. The only purpose of our attempt is favouring the best management of public resources devoted to seismic risk mitigation in Italy and to inform the people living in the proposed priority zones. This last awareness may at least stimulate the restoration of the most vulnerable buildings in the zones involved and, more in general, all the operations that can improve the resistance of buildings to seismic shaking $[18,19]$.

\section{CONCLUSIONS}

An efficient mitigation of seismic risk in Italy can hardly be achieved without a tentative recognition of few priority zones, where the very limited resources now available can be concentrated. The only doubts

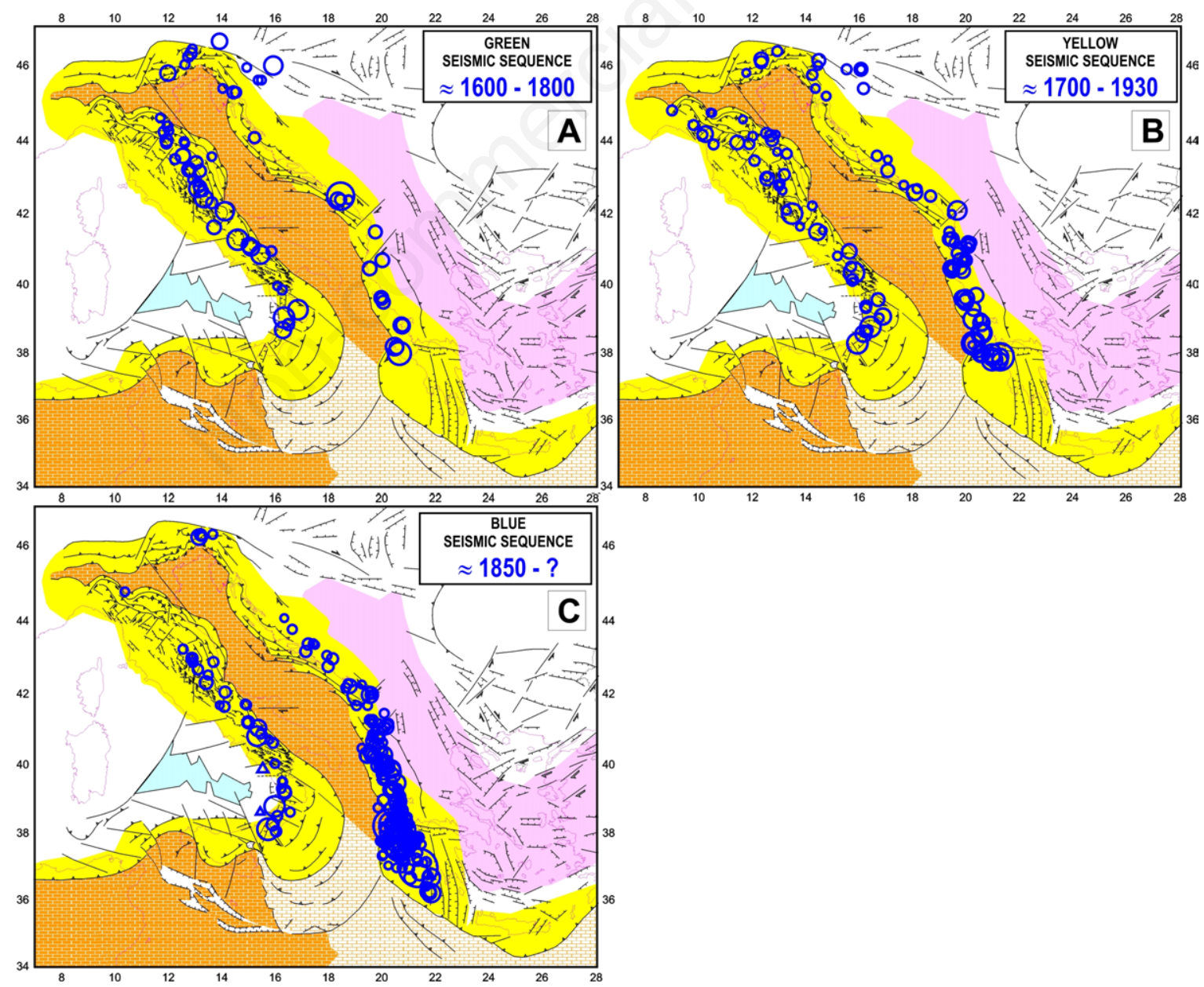

Figure 4. Distribution of the earthquakes with $M \geq 5.5$ that occurred during the last three migrating sequences evidenced in Figure 3. 


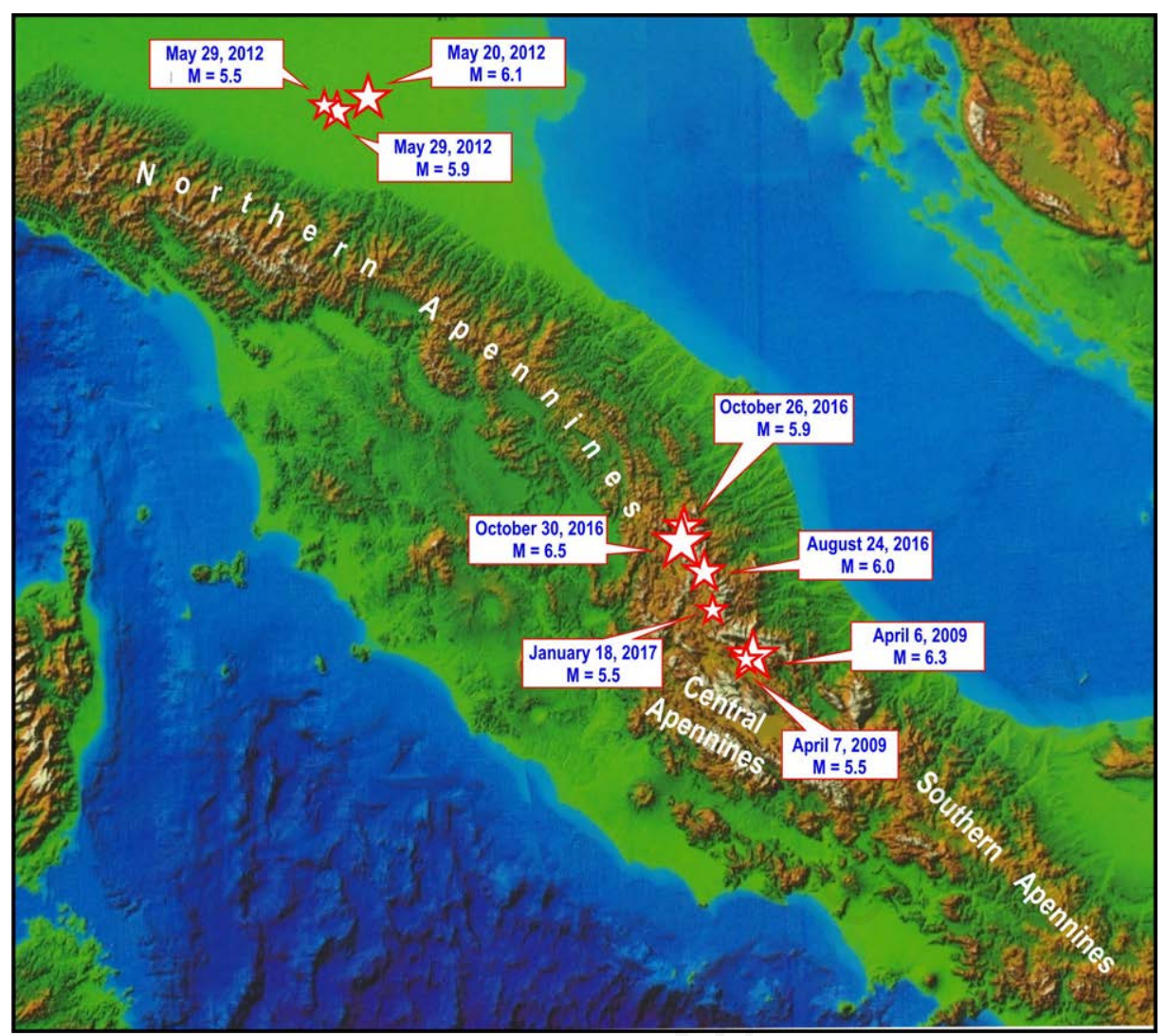

Figure 5. Distribution of major seismicity $(M \geq 5.5)$ in the Italian area between 2009 and January 2017.

about the feasibility of such strategy are due to the possibility that the proposed recognition is unreliable. So, it is opportune to make some considerations about the possible uncertainties that may affect the results of the procedure here adopted.

First of all, it must be pointed out that the procedure here proposed is based on the most reliable approach, i.e. the one that takes into account the deterministic nature of earthquakes and hinges on the concept that the spatio-temporal distribution of major shocks is closely related with the short-term development of tectonic processes. The geodynamic/tectonic context here adopted is the one that best accounts for the huge amount of evidence now available about the recent evolution of the central Mediterranean area, as described in several publications (cited earlier). Furthermore, the reliability of such model is supported by the fact that its implications can provide plausible and coherent explanations for the distribution of the strong earthquakes that have occurred in the periAdriatic regions since 1400 A.D. [8,9]. The fact that the zones recognized as the most prone to next earthquakes have effectively hosted the last 9 strong shocks in Italy considerably encourages to rely on the proposed approach.

\section{REFERENCES}

1. Gruppo di Lavoro MPS. Redazione della mappa di pericolosità sismica prevista dall'Ordinanza PCM 3274 del 20 marzo 2003. Rapporto conclusivo per il Dip.to della Protezione Civile, INGV. 2004. Milano-Roma, pp. 1-65. Available from: http://zonesismiche.mi. ingv.it/.

2. Stucchi M, Meletti C, Montaldo V, et al. Seismic hazard assessment (2003-2009) for the Italian Building Code. Bull Seismol Soc Am 2011;101:1885-911.

3. Marzochi W. Earthquake forecasting in Italy, before and after the Umbria-Marche seismic sequence 1997. A review of earthquake occurrence modeling at different spatio-temporal magnitude scales. Ann Geophysics 2008;51:405-16.

4. Marzocchi W, Amato A, Akinci A, et al. A ten-year earthquake occurrence model for Italy. Bull Seism Soc Am 2012;102:1195-213.

5. Schorlemmer D, Christophersen A, Rovida A, et al. Setting up an earthquake forecast experiment in Italy. Ann Geophysics 2010:53:1-9.

6. Mantovani E, Viti M, Babbucci D, et al. Middle term prediction of earthquakes in Italy: some remarks on empirical and deterministic approaches. Boll Geofis Teor Appl 2012;53:89-111.

7. Viti M, Mantovani E, Babbucci D, et al. Belt-parallel shortening in the Northern Apennines and seismotectonic implications. Int $J$ Geosciences 2015;6:938-61.

8. Mantovani E, Viti M, Babbucci D, et al. Recognition of periAdriatic seismic zones most prone to next major earthquakes: insights from a deterministic approach. In: D'Amico S, ed. Earthquakes and their 
impact on society. Springer Natural Hazard. Switzerland: Springer International Publishing 2016:43-80.

9. Mantovani E, Viti M, Babbucci D, et al, eds. Tentative recognition of the Italian seismic zones most prone to next strong earthquakes (as a tool for reduction of seismic risk). Messina: Mistral Service S.a.S.; 2016.

10. Mantovani E, Babbucci D, Tamburelli C, Viti M. A review on the driving mechanism of the Tyrrhenian-Apennines system: implications for the present seismotectonic setting in the Central-Northern Apennines. Tectonophysics 2009;476:22-40.

11. Mantovani E, Viti M, Babbucci D, et al. Generation of back-arc basins as side effect of shortening processes: examples from the Central Mediterranean. Int J Geosciences 2014;5:1062-79.

12. Viti M, Mantovani E, Babbucci D, Tamburelli C. Plate kinematics and geodynamics in the Central Mediterranean. J Geodynamics 2011;51:190-204.

13. Wells DL, Coppersmith KJ. New empirical relationships among magnitude, rupture length, rupture width, rupture area and sur- face displacement. Bull Seism Soc Am 1994;84:974-1002.

14. Mantovani E, Viti M, Babbucci D, et al. Present tectonic setting and spatio-temporal distribution of seismicity in the Apennine belt. Int J Geosciences 2015;6:429-54.

15. Mantovani E, Viti M, Cenni N, et al. Present velocity field in the Italian region by GPS data: geodynamic/tectonic implications. Int J Geosciences 2015;6:1285-316.

16. Mantovani E, Viti M, Cenni N, et al. Seismotectonics and present seismic hazard in the Tuscany-Romagna-Marche-Umbria Apennines (Italy). J Geodynamics 2015;89:1-14.

17. Viti M, Mantovani E, Cenni N, Vannucchi, A. Post-seismic relaxation: An example of earthquake triggering in the Apennine belt (1915-1920). J Geodynamics 2012;61:57-67.

18. Booth E, ed. Progettazione Sismica di Edifici. Roma: EPC Editore; 2015.

19. Elnashai AS, Di Sarno L, eds. Fundamentals of earthquake engineering. London: John Wiley $\theta$ Sons, Ltd; 2008. 